\title{
New trajectories in urban regeneration processes: Cultural capital as source of human and social capital accumulation - Evidence from the case of Tohu in Montreal
}

\author{
Giorgio Tavano Blessi ${ }^{\mathrm{a}, \mathrm{b}, \mathrm{c}, *}$, Diane-Gabrielle Tremblay ${ }^{\mathrm{d}}$, Marco Sandri $^{\mathrm{c}}$, Thomas Pilati ${ }^{\mathrm{d}}$ \\ ${ }^{a}$ Faculty of Education, Free University, Bozen, Italy \\ ${ }^{\mathrm{b}}$ Faculty of Humanities, University of Trento, Italy \\ ${ }^{\mathrm{c}}$ Faculty of Arts, Markets, and Heritage, IULM University Milan, Italy \\ ${ }^{\mathrm{d}}$ Canada Research Chair on the socio-organizational challenges of the Knowledge Economy, Télé-université, Université du Québec à Montréal, Canada
}

\section{A R T I C L E I N F O}

\section{Article history:}

Received 21 June 2011

Received in revised form 19 September 2011

Accepted 4 December 2011

Available online 13 January 2012

\section{Keywords:}

Urban areas

Urban regeneration

Cultural capital

Human capital

Social capital

\begin{abstract}
A B S T R A C T
Throughout the late 20th and early 21st Centuries, culture has gained increasing importance in strategies designed to deal with new trajectories of urban areas. Post-industrial cities seek to revive former industrial, contaminated and waterfront sites and their city centers, as they are aiming to establish themselves in the new arena of the global market place.

This paper looks at the relationships between investments in cultural resources/activities and urban regeneration processes, and in this respect, how culture can be considered a determinant to the accumulation of human and social capital. It examines the transformation of the Saint Michel district located in metropolitan Montreal. The Saint Michel area is experiencing a radical change in its social, economic and environmental profile due to its transition from the industrial-led development model to the post-industrial model in which investments in cultural and creative activities/industries - particularly the headquarters of Cirque du Soleil and TOHU - La Cité des Arts du Cirque - are supplying new opportunities for the local area in a metropolitan dimension. What impacts does such clustering have on the social and human capital of the vast majority of the populations that live within this area?

Based on a theoretical review and empirical investigation, the paper presents some clarification of the role of cultural investment in the definition of an emerging sustainable social scheme within the community to promote the development of local social and human capital. We know that cultural habits do not change quickly, and our research shows that organizations need to be proactive and seek very actively the participation of the local community if they want to see changes. Our case study highlights the fact that it is important to invest actively in mobilization, local information and promotion and to do so with the cooperation of local community organizations to attain some form of bonding with the local population, have the positive effects expected in terms of involvement in the community and act as a lever for local socio-economic development.
\end{abstract}

(ㄷ) 2011 Elsevier Ltd. All rights reserved.

\section{Introduction}

In recent decades, culture has become increasingly important for strategies designed to deal with new trajectories of urban areas, and in this respect, culture has been used as a 'tool' to revive dismantled industrial and waterfront sites of city centers and derelict areas and as a territorial marketing instrument for a better placing of cities in the post-industrial global market place. The rise of interest in the so called culture-led urban regeneration process has involved cities, and even small towns, which seem to be willing to

* Corresponding author at: Faculty of Arts, Markets, and Heritage, IULM University Milan, Italy.

E-mail address: g.tavano@iuav.it (G. Tavano Blessi). use the process as a 'magical' receipt for a new position in the worldwide competitive arena.

While much attention has been paid to the way in which such urban clusters provide benefits to the economy through tourism or the so called knowledge economy, little attention has been paid to the relationship between these investments in urban districts, particularly the strengthening of their cultural resources/activities and the impact these investments have on the quality of life of the residents in peripheral districts.

Although paying attention to culture may, at first glance, seem favorable to the creation of new opportunities in the economic and infrastructural dimension, there is a growing awareness that it may end up paving the way to developmental initiatives on the social dimension, specifically on issues of social marginalization and 
exclusion (Tremblay \& Tremblay, 2010). Over the past few decades, cities such as Montreal have been developed through strategic planning processes that have tended to concentrate new cultural assets in metropolitan areas (Tremblay \& Tremblay, 2006). In the 1990s, the Northeast district of Montreal was given a boost when it was chosen as the host for circus milieu cluster activities. Rather than joining many other cultural activities in the center of Montreal, Cirque du Soleil and TOHU decided to establish their activities in a district that is home to many immigrants and has a certain level of poverty and exclusion. TOHU is distinctive in that it combines circus arts with an environmental project as well as projects that include the local community in artistic activities and create jobs for community members.

In developing clusters of cultural facilities within metropolitan areas, such as those of the Saint Michel District, a question remains to be answered: What effects for the development of social and human capital does such clustering have on those who live in peripheral regions of the city, such as the Saint Michel District, where there are issues of poverty and difficulty with "visible minority" population integration into the labor market (Klein \& Tremblay, 2010)? This paper seeks to answer this question with the findings of a survey that explores the impacts of the cultural investments in the area. Our findings should provide some initial insights into and tools for measuring the relationship between the development of these concentrations of culture within urban spaces and social and human capital dimensions of the lives of those who live in peripheral districts.

The aim of this paper is thus to determine what conditions are necessary for ensuring an increased participation of the local community in cultural activities, thus contributing to cohesive local economic development rather than exacerbating division within the city, which involves some districts experiencing strong economic development and many cultural manifestations and other districts being left to themselves, with little cultural activity and local development. It is also the aim of this paper to develop a series of indicators for further research on the impact of cultural and creative districts on communities. It is worth noting that the definition of culture adopted in the study is quite broad and includes opportunities provided by the production, promotion, participation and exposition of various forms of art and culture (activities and facilities). These activities and facilities can contribute to the development of new opportunities for the individual, including cognitive dimensions, which lead to the improvement of human capital while bridging and developing connections and thus to a consequent expansion of social capital within the local population.

The article begins by developing a conceptual framework for the study through engaging with the literature on the measurement and impacts of culture-led regeneration. We argue that little research has focused on the way in which these processes positively and negatively affect the human and social capital of populations. The article then presents the methodology for the study and presents the findings. The paper concludes with a synthesis of the research findings and suggestions for future avenues for research.

\section{Conceptual framework: culture and urban regeneration}

There has been an increasing amount of debate over the relationship between culture and local development processes, and in this respect, the role of culture in prompting new opportunities for de-industrialized zones. Research within economic, human, spatial and cultural geography has become progressively aware of the different ways in which culture can affect local development (Tremblay, 2006). What has been in some sense misleading is the role such resources play in boosting new opportunities at both the economic and social levels and how culture plays a key role in the new post-industrial scene.

One of the trends that has characterized the last decade is a massive increase of interest in culture as major policy leverage for urban change (Miles \& Paddison, 2005). Considering the difficulties brought about by standard approaches to strategic urban planning, culture has appeared to many to be a smart move in many respects (Evans, 2009). The construction of urban identity (Gimeno Martinez, 2007), the involvement of the local community (Goldbard, 2006), and the attraction of resources and talent (Florida, 2002) are challenges for which traditional tools seemed to fall short in providing credible solutions and for which culture sounded like a promising approach that was likely to introduce inspirational elements, both at the conceptual and at the policy levels (Landry, 2006, 2008). Moreover, in the breakthrough of the post-industrial transition that is deeply changing the ways in which economic and social value are produced and circulated, culture is playing a new, major role and is by many no longer regarded as an economically marginal sector but as one of the potential engines of the emerging experience economy (Scott, 2000; Baum, Yigitcanlar, \& O'Connor, 2008) and a major factor in local competitiveness (Currid, 2007, 2010). There is, however, a far from unanimous feeling that this emphasis on culture- and creativity-led urban policies is not adequately warranted by the available evidence and by a convincing background of case studies (Bontje \& Musterd, 2009). What seems certain is that culture is not a panacea that somehow magically 'works' to make cities cooler, richer, and trendy (Young, 2006) or creative (Peck, 2005). The idea that culture may have substantial effects on the aforementioned dimensions and possibly others is, in principle, not without a rationale, but why, how and under what conditions this occurs is an issue that must be tackled seriously and systematically. Additionally, the impacts of these initiatives on local communities have not been analyzed to a great extent.

The main conflict between culture and urban transformation processes and local communities occurs between the "creative class' and local society values, necessitating reasoning about culture as an instrumental tool for local development. From the creative class point of view, the emphasis on creativity and creative activities stems from the fact that the latter are those who (according to Florida and others) 'bring the money' in the current scenario or are a means of pursuing a socioeconomic goal (to make cities thrive). However, from the local community's point of view, the emphasis is on the social practices of creativity and their meaning: having the opportunity to live a creative life is an end in itself, and all of its further implications come as a second thought (Markusen, 2006; Markusen \& Schrock, 2006). The literature on the relationships between culture and local development processes has so far given relatively little attention, both at the theoretical and policy levels, to issues related to local community development or to the effect of culture on the accumulation of human capital (Castello \& Domenech 2002; Judoson 2002) and social capital (Glaeser, Laibson, \& Sacerdote 2002; Putnam 2001), while in our view, these are fundamental issues. This lack of attention is at least partly because a proper conceptualization of the role of culture in shaping the codes of rationality for the production and accumulation of intangible assets is still lacking. As Sacco and Tavano Blessi (2009) indicated, the fundamental condition for a feasible culture-led local development ${ }^{1}$ is the presence of social governance mechanisms that encourage individuals and groups to be intrinsically motivated to

\footnotetext{
1 By 'culture-led' local development, authors are referring to a local development process in which cultural production and participation (both directly and in their strategic complementarity with other forms of knowledge-based productive activities) play a driving role similar to that of education in classical endogenous growth models (see e.g., Aghion and Howitt, 1997).
} 
improve collective processes through participation in cultural activities, to foster new forms of sociability, and to link social approval and recognition to commitment. In this respect, culture plays a major role, particularly concerning urban regeneration processes, which usually embrace more dimensions rather than simply the pure economic or infrastructural dimension.

Urban regeneration projects follow the decline of industrialization trends within urban contexts, and the majority claim to follow a new concept of urbanism focused on the diversification of lifestyles and on the quality and variety of services and infrastructures that the post-industrial city can provide. Urban regeneration moves redevelopment a step forward from the pure physical or environmental improvement, inasmuch as it encompasses a multi-sectoral approach to urban works aiming for effects on the economical, social, infrastructural, natural and cultural levels in a long term perspective (see Roberts, 2000).

Starting with the seminal work of Bianchini (Bianchini \& Parkinson, 1994), hundreds of scholars have investigated the role of culture within urban regeneration processes (e.g., Evans, 2004; Miles \& Paddison, 2005; Sasaki, 2010), particularly regarding the relationships among culture, cultural policy, urban physical transformation and economic growth.

Evans has clarified the possible use of culture within urban regeneration schemes, providing an analytical tool for evaluating the use of this resource. According to Evans (2004), there are three different models that incorporate cultural capital into urban regeneration processes:

- Culture-led regeneration, in which culture is seen as an aesthetical and instrumental tool of regeneration.

- Culture and regeneration, in which culture is functional in strategic planning but it is not integrated in the plan.

- Cultural regeneration, in which culture is a structural part of strategic planning, fully integrated in the improvement of the environmental, social and economic spheres.

Given the recent approach to culture-led urban regeneration process, assessment has regarded its effects mostly within the material/tangible spheres (Hemphill, Berry, \& McGreal, 2004) rather than in terms of changes in human values, habits, relationship networks, attitudes and creativity arising from the injection of culture. In recent years, a small number of studies investigating the social and human capital dimensions (SC and $\mathrm{HC}$, respectively $)^{2}$ of culture-led regeneration projects have noted that these projects have either failed to take advantage of such dimensions of capital (Evans, 2004; MacClancy, 1997; Plaza, 2000; Sacco \& Tavano Blessi, 2009), or in other cases, have failed to deliver the social and human capital building activities that they specified within their strategies (Garcia, 2005; Kroller, 1996; Prior \& Tavano Blessi, 2011; Sharp,

\footnotetext{
${ }^{2}$ Human Capital generally refers to the 'competence base' created by education, skills, development and training and the purposeful gathering of information and experience. Social Capital consists of a shared pool of norms, informal rules, conventions and practices connecting members of a group and allowing them to coordinate their actions to reach common interest goals. There are several approaches to $\mathrm{HC}$ and SC, from either social or economic perspectives (see e.g., OECD (Organisation for Economic Co-operation, 1998; Castello \& Domenech, 2002; Judoson, 2002; Levy \& Murnane 1999; Putnam, 2001). HC and SC are forms of capital in that, like physical or natural capital, they can be regarded as stock that increases or decreases depending on whether it is fed by certain types of investment and maintenance. The accumulation is deeply rooted in the characteristics of the social environment, and Sacco and Tavano Blessi underline (Sacco \& Tavano Blessi, 2009) that it depends on whether knowledge and competence are economically and socially rewarded and on whether the social context stimulates people to interact, bridge and binds people and communities, inspires people to be intellectually engaged and curious, and so on. The accumulation of HC and SC depends not only on the previous elements but also on actual experiences and consumption of specific kinds of goods, such as culture.
}

Pollock, \& Paddison, 2005). Such nascent research reveals that many culture-led regeneration projects are not taking advantage of the opportunities that such processes provide for the accumulation of intangible assets, such as human, social and cultural/symbolic capital. The argument for investigating how these assets have either been ignored or generated in cultural-led regeneration processes and how they can be embraced more fully in future processes is important because participation in various cultural activities is significant for communities and individuals in that it provides unique opportunities for non-instrumental, collective sense-making.

\section{Montreal: Saint Michel-case study}

The remainder of this paper presents a study focused on the longterm effects of the culture-led regeneration process in the Montreal Saint Michel area on the HC and SC of residents. The study is based on research on the St-Michel district and TOHU over 5 years (20062011), and more precisely, on the findings of a survey conducted in 2007 that sought to understand the actual effects of ongoing development of the area on residents. First, we provide a brief overview of Saint Michel history and demographic profile in the context of the Cirque du Soleil (CdS) and TOHU sites and Montreal's metropolitan planning process. Further insights into the survey's findings are provided through 14 in-depth interviews conducted in 2007 with government officials and private industry representatives who were responsible for developing and managing a range of issues associated with the culture-led transformation activities in Saint Michel. We chose the Saint-Michel district because it presents characteristics (e.g., urban yet peripheral to the city center; large immigrant population; concentration of cultural assets and activities) that are significant for the evaluation of opportunities provided by the cultural development cluster for social and cultural activities and their impact on individuals in this district.

\section{The Saint Michel district and TOHU, main elements}

The Saint Michel district, which is part of the Villeray-Saint MichelPark Extension, one of the 19 boroughs forming the Montreal Metropolitan Area, is one of Canada's poorest districts. However, the district is undergoing a socio-economic transformation because of the arrival of TOHU and CdS (Tremblay \& Pilati, 2008; TOHU, 2006).

Saint Michel was established during the second half of the 19th century as an autonomous village in the area of Montreal. In 1915, the area became a city with municipal and administrative structures. After the Second World War, the town saw an impressive increase in population, economic activity and infrastructure investments, which would characterize future neighborhood development. The population reached 68,000 , as more people were attracted to the area, causing an increase in demand for workers in the industrial sector. This demand provided opportunities for new members of the population, such as immigrants, arriving in the Montreal area in search of better living conditions. This spontaneous demographic and economic growth was not supported at an institutional level in terms of services, infrastructure and urban planning. For example, the construction of the new six-lane highway connecting Toronto to Quebec City built during the 1960s caused the physical division of the city into two areas, and the lack of definition of a specific planning policy for the areas shows a territory in which economic and residential areas are blended together in a unique mixture.

Starting in the second half of the 1960s, the industrial sector started to decrease in importance. In 1968, a call for a referendum aiming to find better opportunities for the development of Saint Michel led to its administrative inclusion within the city of Montreal. Saint Michel then became part of the Villeray-Saint MichelPark Extension district. The neighborhood lost its independence 


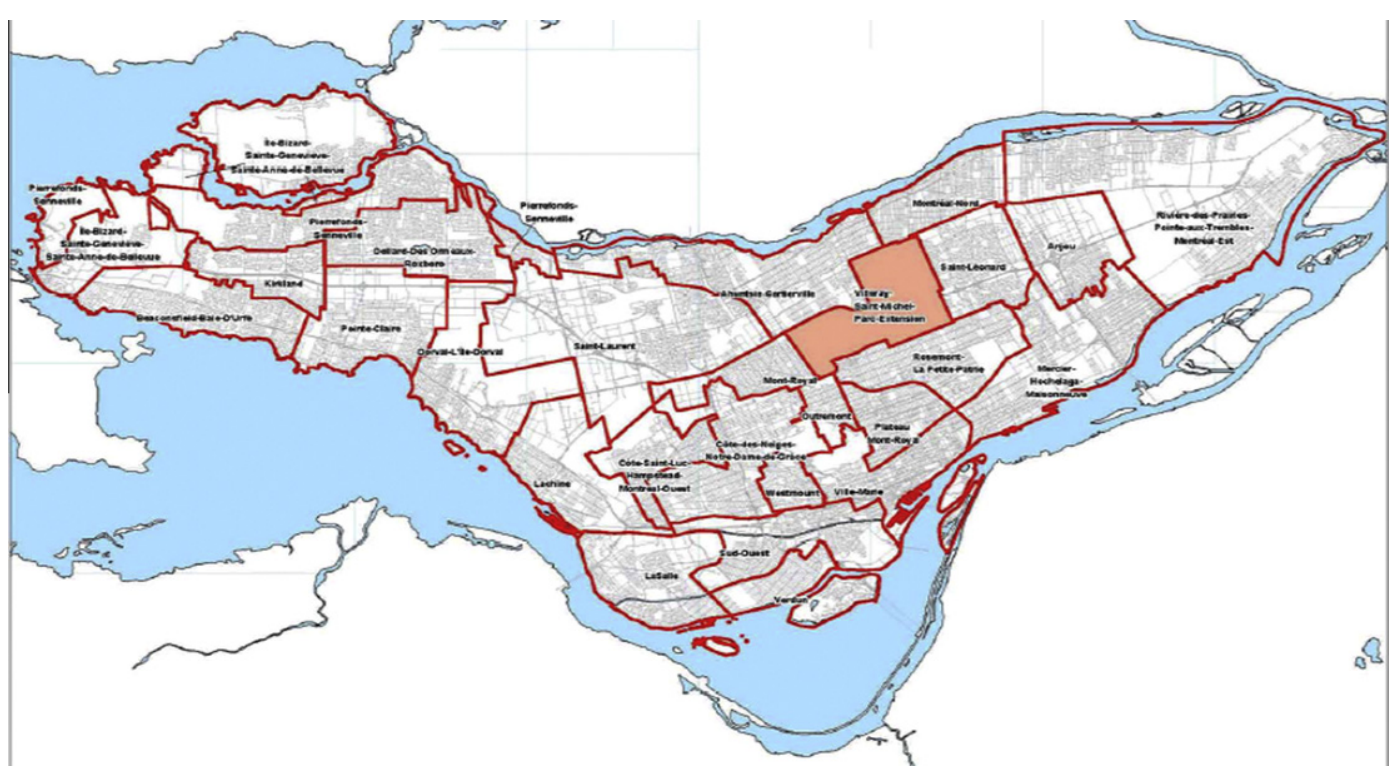

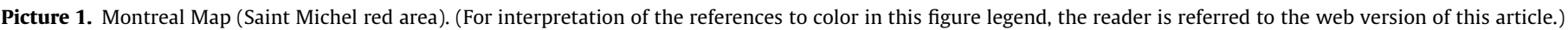

in terms of services and land administration; starting in 1968, the area used for mining activities became a garbage dump, and starting in 1980, a landfill area for all of Montreal, thus creating the second largest landfill area on the entire North American continent.

The 1980s saw the emergence of three phenomena: a decrease in the population due to the closure and delocalization of part of the district's industrial activities; evident cultural and ethnic diversification, which remained one of the main attributes of the area; and environmental issues due to the landfill. The impressive diversification in terms of culture and ethnic groups led to some social problems related to the living conditions of and discrimination against the Saint Michel population during the 1980s. This guided the establishment of community organizations aiming to help local citizens and to improve general conditions in the area. During the 1990s, community organizations planned protests against the environmental problems present in the area, particularly the highway and the landfill area. Saint Michel's population started to contest these developments, and as a result of many demonstrations, the Montreal Council decided to transform the landfill into a greenfield site and urban park, the Saint Michel Environmental Complex (CESM), which, after a gradual transformation, became Montreal's second-largest public park (see Pictures 1 and 2).

In 1997, the most important Quebec private company, Cirque du Soleil, decided to move into the area and establish its new international headquarters. The headquarters provided jobs for 1500 employees and created the 'Cité du Cirque', which would set the course for the transformation of the neighborhood.

\section{La Cité des Art du Cirque - TOHU}

The site includes Cirque du Soleil, the national Circus school (École Nationale du Cirque), TOHU (a nonprofit), and a housing building for artists who come to Montreal to train in the circus arts. Various community and civil society groups were active in relation to the establishment of the Circus in St.-Michel. Many meetings were organized to push for local participation and local employment creation. Additionally, the city asked the Cirque to offer free shows and activities, and this important circus activity has contributed to turning Montreal into an important city for circus arts. In June 2002, the NPO (non-profit organization) changed its name to TOHU and introduced a strategic vision for contributing actively to the development process of the Saint Michel neighborhood and participating in the revitalization of the zone (see Brunelle \& Begin, 2005).
TOHU is positioned in the heart of the Saint Michel district, and like the CdS headquarters, stands on the edge of the environmental complex. Two main indoor and outdoor areas form the center. The building is for the most part shaped around the round performance hall, has approximately 850 seats, and is designed expressly for circus activities. There is also an exhibition area, where visual art exhibitions and community activities are organized. The exterior space is a field for summer shows and can host large events.

In 2003, TOHU officially started business, and given its twofold objective, has produced a wide range of activities that have seen the participation of more than 100000 people every year since its opening. These activities can be subdivided into four main dimensions: circus arts, cultural events, environmental actions (the revitalization of the landfill) and social actions that create jobs and develop the social economy sector. ${ }^{3}$

$\mathrm{CdS}$ and TOHU attract artists, producers and choreographers, and they presently employ 2000 people, making it one of the most important zones involved in training, creation, production and diffusion of circus arts. Our interest in this paper is to see to what extent these activities have had an effect on the rest of the community. TOHU's activities aim to minimize gaps in terms of the cultural capability of the local community to make it possible for individuals to participate actively in rather than simply observe or be altogether excluded from artistic or cultural activities. TOHU makes efforts to integrate the visions of the community. Various civil society and community groups engaged in civil rights, immigration and unemployment issues, as well as integration into employment activities, were associated with the TOHU projects to ensure a bottom-up vision rather than an external or "expert" vision of the challenges related to immigrant employment and exclusion in the district and to develop appropriate activities to increase cultural participation and inclusion, HC, and SC in the community. What the concrete effect of these activities is remains to be seen, and this is the object of the rest of the paper. However, let us first present a map of the St.-Michel zone where TOHU, Cirque du Soleil, an environmental complex, and a Circus school and residence are located (centre d'hébergement on the map) (see Pictures $3-5)$.

\footnotetext{
${ }^{3}$ See Pilati and Tremblay (2008) on Tohu's origins.
} 


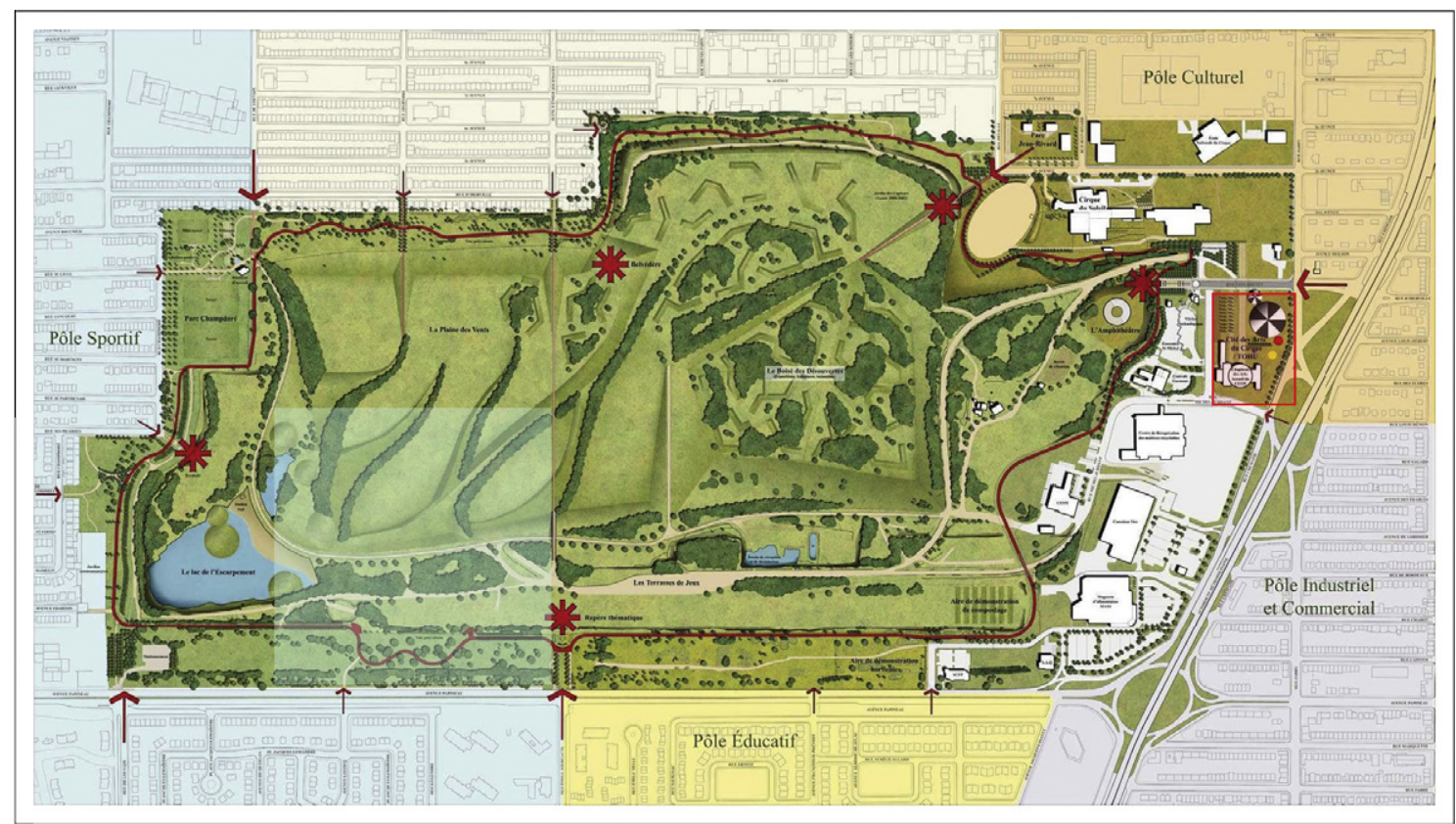

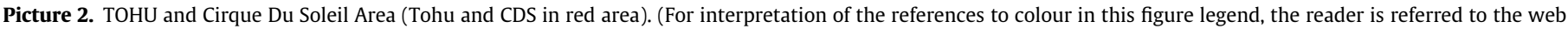
version of this article.)

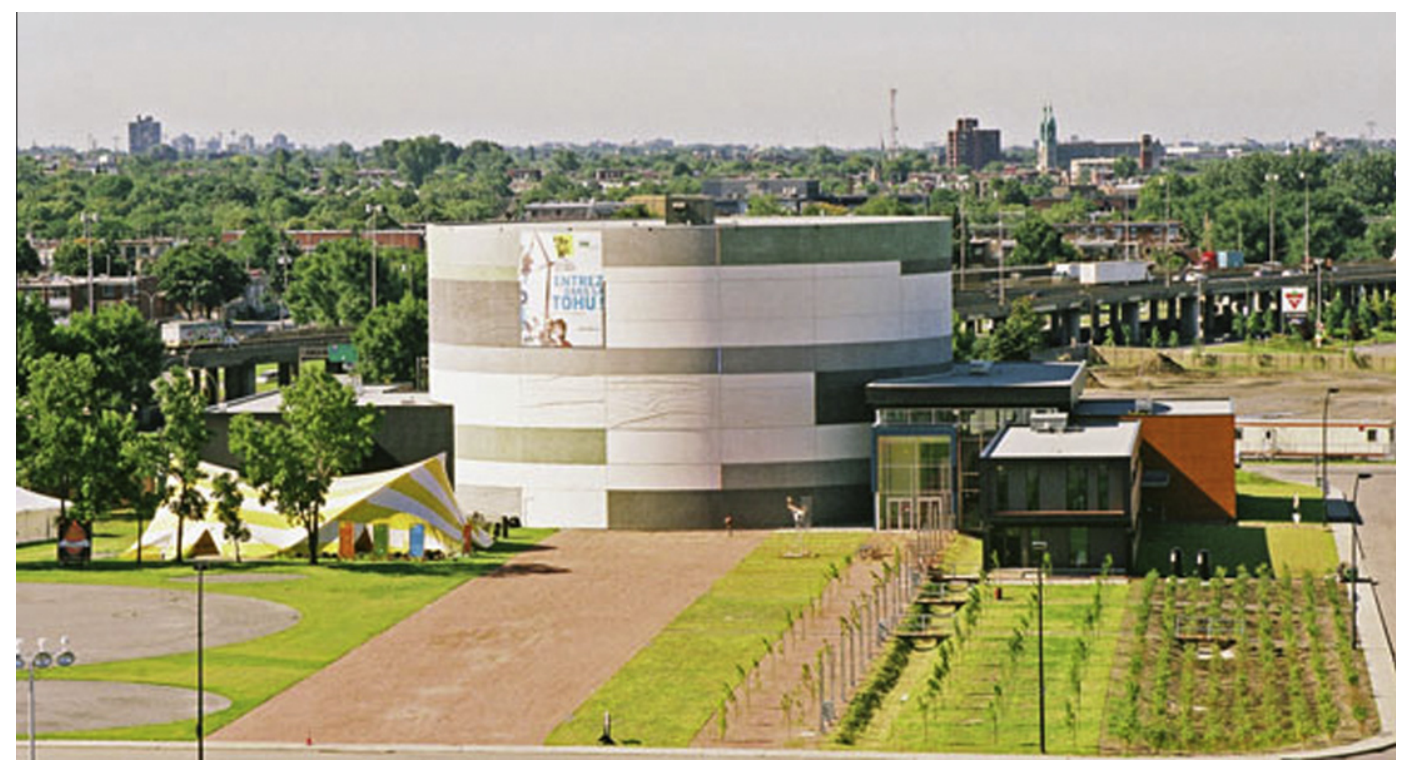

Picture 3. TOHU Building.

\section{Results and discussion of the Saint Michel resident survey}

As mentioned above, the Saint Michel district was selected for the study given its socio-demographic characteristics and the fact it has become the headquarters of TOHU, the National Circus School and Cirque du Soleil. The criteria used to evaluate the impact on Saint Michel follow the theory proposed by Jackson, Herranz, and Kabwasa-Green (2005), who have identified three indicators to measure the cultural vitality of a community, particularly regarding elements such as resident participation and community empowerment. These are as follows:

- the existence (or absence) of cultural engagement activities for individual and groups;
- the direct contribution of citizens to the production of cultural events or activities;

- the local governance system aiming to promote and develop the cultural offer within the urban environment.

The first two criteria seek to provide an opportunity to compare the experience generated by the culture-circus complex development for residents of the district, and they refer to the potential effect of culture-led urban transformation of social capital (e.g., levels of citizens' involvement or the intensity of networks within the community). The third depicts the collaboration between cultural organizations and the community focused on the generation of a culturally rich urban environment. In addition to the three previously mentioned dimensions, a fourth is identified concerning 


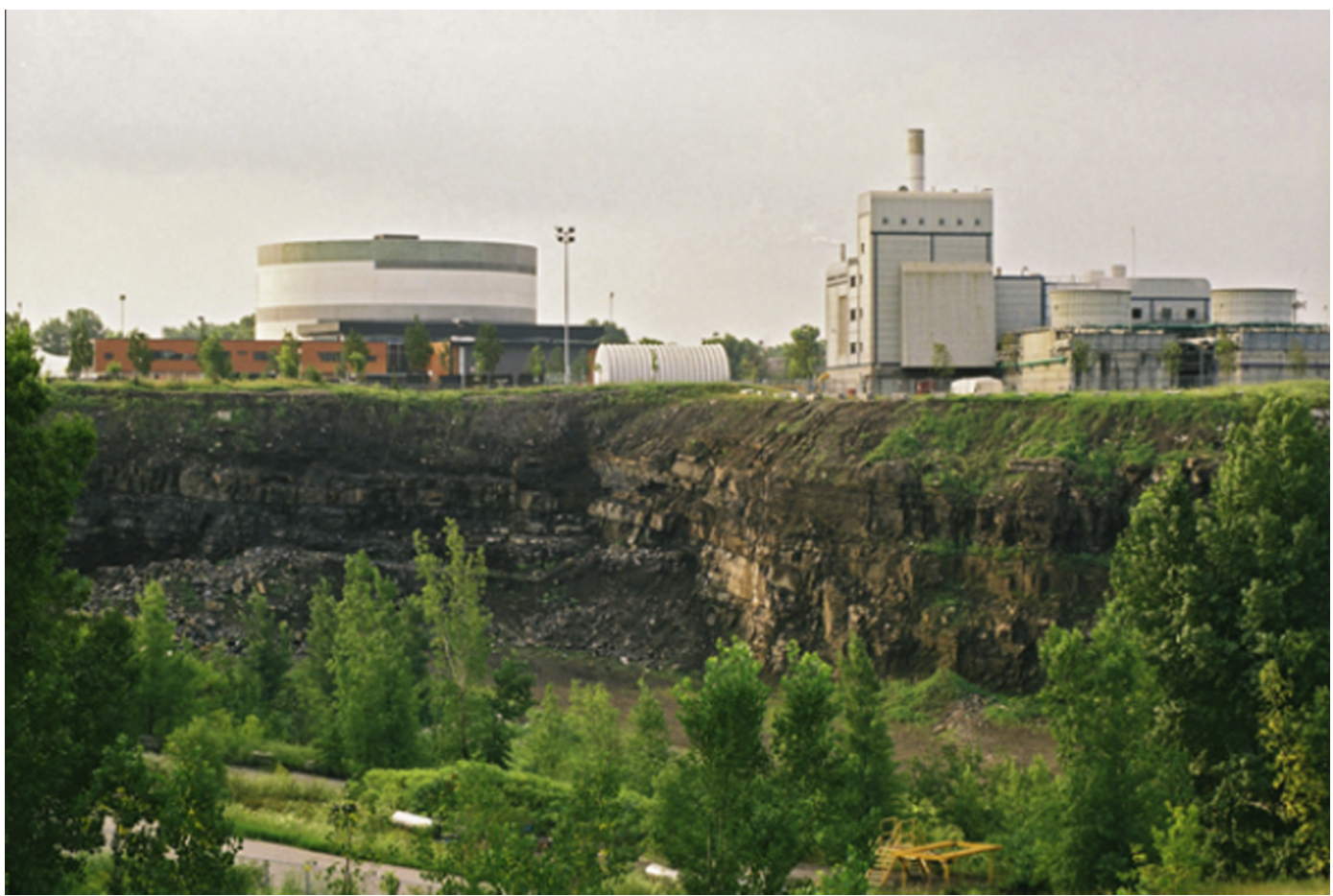

Picture 4. Saint Michel Environmental Complex View.

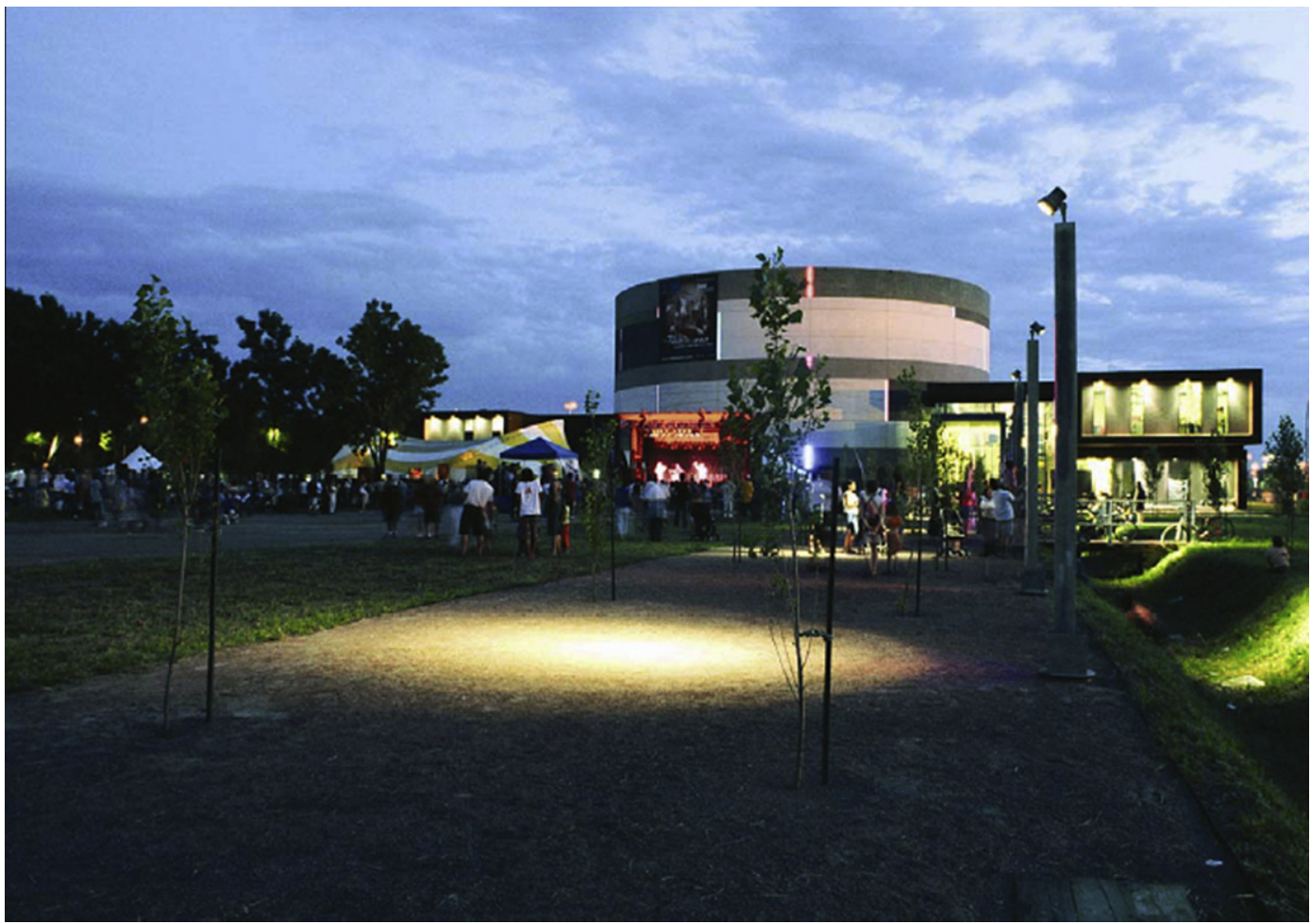

Picture 5. Outdoor Space.

the provision of opportunities in economic and educational terms. Both refer to outcomes provided in HC (e.g., cultural participation resulting in the acquisition of skills and competences).

All criteria were selected to provide insight into the impact of CdS and TOHU on opportunities for Saint Michel residents, which is a priority for both the local government and local organizations. The survey results for these indicators are discussed in this part of the article.

In an attempt to collect survey responses from a broad cross section of residents - 18 years and over - in the selected district, 
Table 1

Key demographic details for the Saint Michel district.

\begin{tabular}{|c|c|c|c|}
\hline Demographic data from 2006 Census & Saint Michel & Villeray-Saint Michel-Park Extension & Montreal \\
\hline Total residential population & 59,378 & 145,485 & 1812,683 \\
\hline Immigrant & $42 \%$ & $41 \%$ & $28 \%$ \\
\hline Non-Immigrant & $57 \%$ & $56 \%$ & $71 \%$ \\
\hline \% Who speak a language other than French or English & $36 \%$ & $34 \%$ & $18 \%$ \\
\hline Average individual income per year & $\$ 18,841$ & $\$ 19,187$ & $\$ 28,205$ \\
\hline Educational level: 9 years - university & $29-13 \%$ & $26-19 \%$ & $15-30 \%$ \\
\hline \% Unemployment of working population & $18.3 \%$ & $19.8 \%$ & $13 \%$ \\
\hline
\end{tabular}

two methods were used: interviews with residents in public areas and interviews collected through local associations that service residents of diverse cultural and linguistic backgrounds.

We used a cross-sectional survey to gather quantitative data rather than qualitative data to enable the further evaluation of the impact of the cultural investments in the area. In addition, a written document made it possible to avoid a possible misunderstanding of the research questions due to the massive linguistic diversity. Interviews were conducted to enhance the data gathered with information on the planning process in the area, receive insight from local stakeholders into the impact of the investments made in the area and compare the outcomes supplied from the survey to these actors' views. One might think there might be a certain bias introduced by the proximity of local organizations to the survey respondents and that this could constitute a limit of the research, but this is a characteristic of the local situation; as the local respondents were placed in a context in which they were totally free to express their views (anonymous questionnaires and absence of the organizations' representatives when they filled them in), we assume that they were placed in an environment conducive to trusting the survey administrators and that this may actually add consistency to the general results.

One of the main challenges for survey-based studies is to find respondents and convince them to complete the survey, and this is why we solicited some local organizations and had some questionnaires filled in at local meetings. The survey was distributed to 274 residents in the area, and 201 surveys were completed. Almost $50 \%$ of questionnaires were collected through local community organization meetings, and while the survey sample is not statistically representative, it reflects quite closely the demographic characteristics of the district, including the gender dimen$\operatorname{sion}^{4}$ (see Table 1 and Table 2).

\section{Indicator 1: social activity and participation}

In the case of the first indicator, the aim was to evaluate the impact of the establishment of the CdS and TOHU. The focus was centered on the activities developed and opportunities offered to the local population to increase participation in social activities.

A fairly high proportion of respondents indicated that opportunities for social activity and individual participation had increased as a result of TOHU (see Table 3). This is the result of the efforts of TOHU, but it is also the outcome of the participatory approach taken since the beginning of the development of the site. The participatory approach was helpful in setting up the strategy of the organization, which was followed by the definition of a strategic social plan in 2003, which included actions and aims for involving the local population. In this respect, TOHU created a position that

\footnotetext{
${ }^{4}$ While black males constitute the group that has the most difficulty integrating into employment, other groups who don't speak French or English well (Iranians, Latinos, etc.) can also have difficulties, and while immigrant males usually have more difficulty than females in integrating into the labor market, at least in the younger groups, all immigrants have a higher unemployment rate than the local population. However, the portion of the local population with low levels of education also has difficulties in terms of unemployment and poverty.
}

could be defined as a 'social planner' whose purpose was to be part of the local environment and develop a network between TOHU and local communities and organizations. TOHU has been invited to attend the meeting of the "Chantier de revitalisation sociale et urbaine de Saint Michel ${ }^{5}$ and is also working with social organizations to improve the social economy of the area.

Despite the community development initiatives, the majority of respondents felt that TOHU's development had not increased their opportunities for social activity or individual participation in social activity. However, the $37 \%$ of respondents that did indicate that their opportunities had changed is not negligible because it is not easy to change a population's habits. For those who indicated no change, it is possibly because it takes time to develop relationships and because some people may simply consume the cultural products offered to them and are not necessarily trying to increase the number of their relationships or their social capital. However, the 14 in-depth interviews also indicate that the area is still suffering from a lack of meeting places, opportunities and public transportation (bus-metro) to the area. Respondents also identified language difficulties with French and English as a second language, and this is seen by respondent as a key barrier to involvement in social activities.

\section{Indicator 2: sense of involvement}

A sense of involvement is one of the key issues in the process of bridging and bonding members of communities, particularly for those communities in which it is possible to observe social fragmentation in terms of language, religion, habits and norms. The opportunities provided by not only attending cultural activities but also being an active participant in them will prompt the establishment of social networking, mutual acquaintance and relationships with other individuals and communities. Culture may contribute to the involvement of residents given the fact that its mechanism of involvement relies entirely upon social dynamics. To increase the stock of social capital, it is necessary for individuals to devote resources (e.g., money, time, and energy) to the creation and circulation of relational and social participation opportunities and culturally mediated social interaction activities that cause the strengthening of social ties. We can therefore say that the involvement dimension of cultural activities makes a contribution to the stock of SC. If cultural policies and actions are designed to foster the relational dimension in specific ways, then by suitably crafting interaction modes, culture may make a significant contribution to the accumulation of a specific kind of SC, such as that of the "bridging' or 'bonding' type. What are needed in this particular respect are participatory types of cultural projects and initiatives that are carried out at the community level and that satisfy relational needs (see Paris \& Baert, 2011; Sacco \& Tavano Blessi, 2009).

Culture can thus become a determinant in creating SC.

Although the percentages are lower here, a sizeable proportion of respondents declared that thanks to the activities organized by

\footnotetext{
5 The Chantier de revitalisation sociale has involved more than 1000 Saint Michel citizens in the decision-making process for the establishment of the social plan. CdS and TOHU are promoting actions with the Chantier and pilot projects in the neighborhood schools.
} 
Table 2

Profile of the survey respondents from Saint Michel.

\begin{tabular}{ll}
\hline Demographic data from Survey respondents & Saint Michel \\
\hline Total survey respondents & 201 \\
\% males & 53 \\
\% females & 47 \\
Age range & $18-n$ \\
\% unemployed or inactive & 23 \\
\% working or in labor market & 77 \\
\% of residential population that are born overseas & 46 \\
\% of respondents with less than high school - & $35-8$ \\
$\quad$ university & \\
Range of years that respondents have lived in the & Since 1997 or \\
$\quad$ suburb & before \\
\hline
\end{tabular}

Table 3

The CdS and TOHU's effect on respondents' opportunities for social activity and participation.

\begin{tabular}{lll}
\hline Measures & \multicolumn{2}{l}{$\begin{array}{l}\text { Saint Michel } \\
(n=201)\end{array}$} \\
\cline { 2 - 3 } & Increased & $\begin{array}{l}\text { No } \\
\text { Change }\end{array}$ \\
\hline $\begin{array}{l}\text { \% of respondents indicating that opportunity for social } \\
\text { activity [increased/did not change] as a result of the } \\
\begin{array}{l}\text { CdS - TOHU development } \\
\text { of respondents indicating that their individual } \\
\text { participation in social activity [increased/did not } \\
\text { change] as a result of the CdS - TOHU development }\end{array}\end{array}$ & 61.1 \\
\hline
\end{tabular}

Table 4

The CdS TOHU effect on sense of involvement.

\begin{tabular}{lll}
\hline Measures & \multicolumn{2}{l}{$\begin{array}{l}\text { Saint Michel } \\
(n=201)\end{array}$} \\
\cline { 2 - 3 } & Increased & $\begin{array}{l}\text { No } \\
\text { change }\end{array}$ \\
\hline $\begin{array}{l}\text { \% of respondents indicating cultural activity at the CdS } \\
\text { TOHU area [increased/did not change] opportunities } \\
\text { for social networking }\end{array}$ & 40.2 & 59.8 \\
$\begin{array}{l}\text { \% of respondents indicating that their mutual } \\
\text { acquaintance/relationship with other individuals } \\
\text { [increased/remained unchanged] as a result of the } \\
\text { cultural activity at the CdS TOHU area }\end{array}$ & 15.9 & 84.1 \\
\% of respondents indicating that their mutual \\
$\begin{array}{l}\text { acquaintance/relationship with other local } \\
\text { communities[increased/remained unchanged] as a } \\
\text { result of the cultural activity at the CdS TOHU area }{ }^{\mathrm{c}}\end{array}$ \\
\hline
\end{tabular}

a Question asked: has your participation in voluntary social service work/association in Saint Michel area increased after CdS and TOHU projects arrived in your area? Yes or no?

b Question asked: has your acquaintance to the others people living in Saint Michel area increased after CdS and TOHU projects arrived in your area? Yes or no?

c Has your acquaintance with the various communities living in Saint Michel area increased after CdS and TOHU project arrived in your area? Yes or no?

TOHU, they found new and more opportunities for enlarging their relational framework and social networks (see Table 4). This high percentage of answers could be linked to the method of survey administration, given the fact that questionnaires were provided during community meetings. To avoid any distortion and influence by the local community organizations, the process has been managed with only the presence of the researchers in the room. The local community centre manager was asked to leave the room in order to allow interviewees to provide their opinion freely. Additionally, the questionnaires were anonymous, so there was no way of tracing the respondents, and for the respondents to know that it was a good occasion for giving feedback on the project in the hopes of eventually making it better. Once more, the reasons for this result are varied and include such things as language difficulties, which represent a significant constraint in terms of personal interactions during these activities and could explain the absence of change that a sizeable percentage of respondents report. Others noted that the structures of some of the activities organized were not geared toward meeting new people. This should be the case for such activities, as for proper circus shows and events, but it is also true that more than $50 \%$ of the annual program is centered on activities in which the community is the core target. In addition to this, we must recall the agreement between TOHU and the Municipality of Montreal, which states that TOHU must offer 40 cultural events (theatre and shows) and 10 visual art exhibitions every year. These activities are free, as the city government finances them, and most of them are realized during the summer with intense bottom-up community involvement. During those activities, communities are invited to present their cultural expression, and TOHU supplies all technical and organizational assistance for the events.

In addition, the increased opportunities for social networking in the area can be partially linked to the work of community organizations, particularly TOHU. Since the establishment and development of TOHU, the collaboration between community centers has been one of the elements of the social strategy (see Brunelle \& Begin, 2005). An example of this strategy is the Sunday afternoon summer activities organized in the TOHU outside space designed for shows and performances, in which events are planned and developed in collaboration within local communities, allowing them to present their own shows, or community events, such as the closing summer event called Falla, which has an attendance of over 10.000 Saint Michel residents every year.

The aim is to create bonds within the Saint Michel communities that share a common language and face similar socio-economic difficulties and bring them to network together. As researchers have highlighted, the groups and associations that can generate SC also carry the potential to constrain individuals' actions and exclude others (Portes, 1998; Portes \& Landolt, 1996). The survey revealed the limited extent to which respondents were able to utilize their involvement in social activities as a means for developing relationships with other groups and communities. As for explanations for why many people experienced no change in terms of social networking or relationships, it takes time to develop relationships, many of the attendees are not necessarily "social persons" and may have difficulty in engaging in relationships, and some people simply "consume" cultural products or attend events and are not looking to enlarge their social networks.

\section{Indicator 3: cultural participation}

The questionnaire also assesses whether CdS TOHU's activities have changed community members' levels of cultural participation and how frequently they participated in cultural activities.

Here, the change is very important because over half of the interviewees declared that their participation in cultural events (e.g., festivals and street events) had increased following the development of TOHU and open-air facilities (see Table 5); this increase

\section{Table 5}

Change in cultural participation - number of events attended - as a result of the CdS TOHU development.

\begin{tabular}{lll}
\hline Measures & \multicolumn{2}{l}{$\begin{array}{l}\text { Saint Michel } \\
(n=201)\end{array}$} \\
\cline { 2 - 3 } Increased & $\begin{array}{l}\text { No } \\
\text { change }\end{array}$ \\
\hline $\begin{array}{l}\text { \% of respondents indicating that their cultural } \\
\text { participation [increased/did not change] as a result } \\
\text { of the CdS TOHU development }\end{array}$ & 50.7 & 49.3 \\
\hline
\end{tabular}


Table 6

Frequency of cultural participation at CdS TOHU.

\begin{tabular}{ll}
$\begin{array}{l}\text { Respondents participated in }[0,1,2,3,4,>5] \text { events } \\
\text { (exhibitions, concert, fairs, conferences, sports events, etc.) } \\
\text { held in the framework or site of CdS TOHU each year }\end{array}$ & $\begin{array}{l}\text { Saint Michel } \\
(n=201) \\
\% \text { of } \\
\text { respondents }\end{array}$ \\
\hline 0 & 33.8 \\
1 & 19.9 \\
2 & 13.9 \\
3 & 9.0 \\
4 & 6.0 \\
$>5$ & 15.4 \\
No answer & 2.0 \\
\hline
\end{tabular}

Table 7

The CdS TOHU's effect on employment and educational opportunities.

\begin{tabular}{llll}
\hline Measures & \multicolumn{2}{l}{ Saint Michel (n=124) } \\
\cline { 2 - 4 } & $\begin{array}{l}\text { Increased/ } \\
\text { improved }\end{array}$ & $\begin{array}{l}\text { Decreased/ } \\
\text { worsened }\end{array}$ & $\begin{array}{l}\text { Remained } \\
\text { unchanged }\end{array}$ \\
\hline $\begin{array}{l}\text { \% of respondents indicating local } \\
\text { employment opportunities } \\
\text { [increased/decreased/did not } \\
\text { change] as a result of the CdS }\end{array}$ & 29.6 & 10.4 & 60 \\
$\begin{array}{l}\text { TOHU development } \\
\text { of respondents indicating local } \\
\text { learning opportunities } \\
\text { [increased/decreased/did not } \\
\text { change] as a result of the CdS }\end{array}$ & 31.8 & 9.8 & 58.4 \\
$\quad$ & & & \\
\hline
\end{tabular}

in participation is enormous, given the fact that these types of habits are not easy to change.

The rate of participation in cultural events provides a straight measure of the intensity with which the local community takes advantage of existing opportunities or activities, and therefore, of the actual production of relational outcomes (related to social capital) and of competences and skills (related to human capital). In the present study, cultural participation has been measured ex post, i.e., after the projects and events have been carried out, and has entailed asking specifically how many times the person participated in any event (exhibitions, concert, social event) held in the TOHU area (see Table 6).

These increased levels of participation can be seen as an important outcome of TOHU not only in terms of events organized (more or less commercial, or sophisticate, in cultural terms) but also due to the intense promotion and social marketing campaign observed since the beginning of the activity. Part of the strategic plan is devoted to actions that should be taken to increase the participation of locals in activities. For example, a 'door to door' promotion policy has been used in the neighborhood for shows and events; public meetings in community and organization offices are held to present activities in general, free show tickets are provided, to the association, and prepaid transportation, such as bus transportation, is made available for show attendance or visits to the environmental complex.

Since 2003, there has been a growing number of cross-cultural events that have included residents from the district and enlarged the potential audience for cultural activity. These actions have decreased two of the main determinants affecting access to cultural assets. Cultural participation levels correlate with demographic factors such as income, education and age, with increased levels of these factors usually being associated with increased levels of participation (Ogrodnik, 2000). This relationship is driven by a diverse range of factors, from the negative effect that lower income status can have on access to participation in much of the 'user pays' cultural opportunities to the more complex relationship between learning and cultural participation. Just as learning provides the tools with which to understand and articulate cultural activities, particularly their complex codes and semantic languages (e.g., modern art), cultural participation through its consumption provides increased familiarity with and understanding of these codes and language, adding to an individual's stock of HC (Ferilli, Sacco, \& Tavano Blessi, in press). In the case of Saint Michel, it is possible to observe that despite the low income and education level of the population, the presence of the organization and the activities has positively influenced the population's willingness to participate in cultural activities.

\section{Indicator 4: employment and learning opportunities}

To date, little attention has been paid to the local employment and education opportunities that are provided by culture-led urban transformation processes (OECD, 2005). Such opportunities are directly related to the accumulation of HC and SC. Learning even the most basic language, social and practical skills adds to an individual's accumulation of $\mathrm{HC}$ by increasing their capacity to live an independent life. The types of learning opportunities that arise from culture-led regeneration processes extend well beyond formal education opportunities (e.g., schooling) to the learning opportunities that emerge from consumption and participation in cultural goods and experiences. Employment provides an individual with the potential for fuller participation in social, cultural and economic life and allows individuals to enhance their skills and strategies to be used in the pursuit of life satisfaction and lifestyle choices.

Almost one third of the sample stated that after the organization settled in the area, they observed an increase in employment and learning opportunities. Approximately 2000 jobs were created that were directly related to Cirque du Soleil and TOHU (see Table 7). Many other jobs and new firms offered employment for the purpose of providing basic services (such as food or cleaning services) and more sophisticated employment that related to the management of the technical plants. From the interviews, we learned that CdS and TOHU have organized training labs and defined specific circus activities courses in collaboration with local organizations. The aim of these courses was twofold: to provide an opportunity for the local population to approach such art expression and learn more about it and to explore the option of employment of some of the local population by the two organizations. As Mayor of the Arrondissement, Annie Samson, explained: "The City of Circus arts counts over 1500 jobs in the arrondissement, making arts and entertainment one of the most important sectors of economic activity at the local level".

These findings suggest that the two organizations' development is generating a need for a particular type of skilled labor that provides opportunities to a portion of the local residents and is reconfiguring the local employment and education scenes.

Interviews suggest that attention is being paid to the ways in which TOHU development might contribute to the generation of more equitable local employment and learning opportunities. Having said this, no specific policies or programs have been developed to address the learning and employment challenges of the socioeconomically disadvantaged, for whom employment opportunities may be limited by low educational attainment and a limited capacity to learn needed skills.

\section{Conclusions}

This paper has focused on the transition from the industrial-led development model to the post-industrial model, in which investments in cultural and creative activities/industries - in this case, at the headquarters of Cirque du Soleil and TOHU in particular - are 
supplying new opportunities for the surrounding area but also have an impact in the metropolitan dimension. We saw that this had rather important impacts on the local community in terms of cultural participation, especially because it is obvious that cultural habits do not change quickly.

Several studies attempted to highlight the elements influencing cultural participation and habits (see Diniz and Machado, 2011; Ateca-Amestoy, 2008). In this respect, cultural consumer behavior can be framed as a decision made by the individual that is affected by the living environment and subjective characteristics, e.g., personal tangible (e.g., economic) and intangible (e.g., education) resources' effects on participation, past experience, etc. As Grossi et al. underline (Grossi, Sacco, Tavano Blessi, \& Cerutti, 2011), in the presence of low educational levels and low economic and occupational status, the reason to participate in cultural activities is usually related to enjoyment and pleasure, with no evolution in terms of taste and habits. On the contrary, frequent attendees tend to be those who are more educated and have higher incomes or occupational statuses, which confirms the presence of a sort of cultural omnivore dynamic for all types of cultural provisions. Given these facts, it is difficult to change cultural habits overnight, and organizations need to be proactive and actively seek the participation of the local community if they want to see change over time.

Here, the policy of participation and free shows has obviously had an impact, which shows the fundamental importance of strategic coordination among local administrations, cultural actors and community organizations in providing socially oriented cultural events. This is a very important result, given the lower economic, educational and social status of most of the population of Saint Michel.

In this respect, TOHU has put much energy into mobilization and local information and promotion, all very clearly oriented toward the local population and performed in cooperation with local organizations. We consider this an important part of the explanation for the increased participation. Our results highlight the fact that the strong focus on an organization's bond with the local population can have positive effects on its integration in the community and on its role as a leverage for local socio-economic development.

As Nussbaumer and Moulaert (2004) highlight, culture may perform effectively as both a cohesive and a networking social factor, satisfying several human and social needs and addressing and improving quality of life and well-being (Grossi, Tavano Blessi, Sacco, \& Buscema, in press). However, as our research has shown, it will only deliver these results under certain conditions. Based on the study's findings, it can be argued that the CdS and TOHU development has contributed positively to the SC and HC of some respondents through increased social relations and participation, increased social networks and acquaintance with others, increased employment and education opportunities, and increased cultural participation. However, our analysis also has shown that it has had either no or less desirable consequences for a good proportion of respondents.

The aim of the paper was to provide some theoretical and empirical observations on the role of cultural investment in the definition of a new social framework within the community, and our case study supports the idea that culture-led development contributes to the enhancement of the stock of local social and human capital for a largely marginalized immigrant community.

As Evans and Shaw (2007) underline, "put simply, culture is being seen by some policy makers and planners as an insurance policy against future decline, and by some investors (private and public) as a value-added distinction and as an accelerator of development". While this may sometimes be the case, we cannot consider that this is a solution in all cases, but it surely has had an important impact in the case of TOHU and CdS, largely because of the size of the two organizations, but also because of the strong participation of the local community organizations. Indeed, it is not only large cultural organizations (such as Art museums, Libraries or other such organizations) that offer exhibits or services in this district but also two organizations that seek to be embedded in the community and put forward mechanisms to ensure active participation of the local population (e.g., individuals of all ages, families in many family events, and teenagers at many music shows) in events which are designed with a participatory objective in mind (e.g., collective paintings, circus art demonstrations with participation of the population, and the Falla fiesta).

We can conclude that urban regeneration projects should be based on a precise analysis of the previously mentioned conditions to set up an integrated approach to urban operations; they should plan in such a way that institutions and social, economical and environmental actors and stakeholders will take part in the project from the early stage of the idea to the final plan. The results should ideally be measurable, and this should lead towards specific objectives that can be monitored (such as those in the tables above) and possibly also to elements of sustainable development theories.

\section{Acknowledgements}

The authors wish to thank the TOHU Staff and, particularly, Mme Camille Begin for her invaluable help and for the case study documentation. We are also very grateful to all Saint Michel local community organizations that collaborated to the research. We owe gratitude to two anonymous referees for their comments and suggestions. None of the above are implicated in any way in the evaluations and opinions expressed in the present paper, for which the authors take complete responsibility.

\section{References}

Aghion, P., \& Howitt, P. (1998). Endogenous growth theory. Cambridge, Mass.: The MIT Press.

Ateca-Amestoy, V. (2008). Determining heterogeneous behavior for theater attendance. Journal of Cultural Economics, 32, 127-151.

Baum, S., Yigitcanlar, T., \& O'Connor, K. (2008). Creative industries and the urban hierarchy: The position of lower tier cities in the knowledge economy. In: T Yigitcanlar, K. Velibeyoglu, \& S. Baum (Eds.), Knowledge-Based urban development: Planning and applications in the information era. IGI Global, Information Science Reference, United States of America, Pennsylvania Hershey, pp. 42-57.

Bianchini, F., \& Parkinson, M. (1994). Cultural policy and urban regeneration: The West European experience. Manchester: Manchester University Press.

Bontje, M., \& Musterd, S. (2009). Creative industries, creative class and competitiveness: Expert opinions critically appraised. Geoforum, 40(5) 843-852.

Brunelle, M., \& Begin, C. (2005). Circus, environment and community: A quest for balance. Wochi Wochi, 8, 19-27.

Castello, A., \& Domenech, R. (2002). Human capital inequality and economic growth: Some new evidence. The Economic Journal, 112(478), 187-200.

Currid, E. (2007). The Warhol economy. Princeton: Princeton University Press.

Currid, E. (2010). Symposium introduction - Art and economic development: New direction for the growth of cities and regions. Journal of Planning Education and Research, 29, 257-261.

Diniz, S. C., \& Machado, F. (2011). Analysis of the consumption of artistic-cultural goods and service in Brazil. Journal of Cultural Economics, 35, 1-18.

Evans, G. (2004). The contribution of culture to regeneration in the UK: A review of the evidence. In Proceedings of third international conference on cultural policy research, August 25-28, Montreal.

Evans, G., \& Shaw, P. (2007). Literature review: Culture and regeneration, arts research. Digest no. 37.

Evans, G. (2009). Creative cities, creative spaces and urban policy. Urban Studies, 46, 1003-1040.

Ferilli, G., Sacco, P. L., \& Tavano Blessi, G. (in press). Cities as creative hubs: From the instrumental to the functional value of culture-led development processes'. In: J. Nijikamp, G. Fusco (Eds.), Sustainable city and creativity: Promoting creative urban initiatives. London: Ashegate.

Florida, R. (2002). The rise of the creative class. New York: Basic Books.

Garcia, B. (2005). Deconstructing the city of culture: The long-term cultural legacies of Glasgow 1990. Urban Studies, 42, 841-868.

Gimeno Martinez, J. (2007). Selling avant-garde: How Antwerp became a fashion capital (1990-2002). Urban Studies, 44, 2449-2464. 
Glaeser, E. L., Laibson, D., \& Sacerdote, B. (2002). An economic approach to social capital. The Economic Journal, 112(483), 437-458.

Goldbard, A. (2006). New creative community. Oakland, CA: New Village Press.

Grossi, E., Sacco, P. L., Tavano Blessi, G., \& Cerutti, R. (2011). The interaction between culture, health and psychological well-being: Data mining from the Italian culture and well-being project. Journal of Happiness Studies, 6(4), 387-410.

Grossi, E., Tavano Blessi, G., Sacco, P. L., \& Buscema, M. (2011). The interaction between culture, health and psychological well-being: Data mining from the Italian culture and well-being project. Journal of Happiness Studies.

Hemphill, L., Berry, J., \& McGreal, S. (2004). An indicator-based approach to measuring sustainable urban regeneration performance. Part 1. Conceptua foundations and methodological framework. Urban Studies, 41(4), 725-755.

Jackson, M. R., Herranz, J., \& Kabwasa-Green, F. (2006). Cultural vitality in communities: Interpretation and indicators. Washington, DC: Urban Institute.

Judoson, R. (2002). Measuring human capital like physical capital: What does it tell us? Bulletin of Economic Research, 54, 209-231.

Klein, J. L., \& Tremblay, D. G. (2010). Can we have a "Creative City" without forgetting social cohesion? Some avenues of reflection. PLAN Canada St-John's University.

Kroller, E. M. (1996). Expo 67: Canada's Camelot? In: Proceedings of the British association for Canadian studies annual conference (pp. 1-14). Exeter, University of Exeter.

Landry, C. (2008). The creative city. A toolkit for urban innovators (2nd ed.). London: Earthscan (first ed. 2000).

Landry, C. (2006). The art of city making. London: Earthscan.

Levy, F., \& Murnane, R. (1999). Are there key competencies critical to economic success? The economic perspective. Paris: OECD - Organisation for Economic Cooperation and Development.

MacClancy, J. (1997). The museum as a site of contest: The Bilbao Guggenheim. Focal Journal of Anthropology, 1(7), 271-278.

Markusen, A. (2006). Urban development and the politics of creative class: Evidence from the study of artists. Environment and Planning A, 38, 1921-1940.

Markusen, A., \& Schrock, G. (2006). The artistic dividend: Urban artistic specialization and economic development implications. Urban Studies, 43, 1661-1686.

Miles, S., \& Paddison, R. (2005). Introduction: The rise and rise of culture-led urban regeneration. Urban Studies, 42, 833-839.

Nussbaumer, J., \& Moulaert, F. (2004). Integrated area development and social innovation in European cities. City, 8(2), 249-257.

OECD (Organisation for Economic Co-operation and Development) (1998). Human capital investment: An international comparison. Paris: OECD.

OECD (2005). Culture and local development. Paris: OECD.

Ogrodnik, L. (2000) Pattern in Culture consumption and Participation Ottawa, Statistics Canada.
Paris, D., \& Baert, T. (2011). Lille 2004 and the role of culture in the regeneration of Lille Métropole, Town. Planning Review, 82, 29-44.

Peck, J. (2005). Struggling with the creative class. International Journal of Urban and Regional Research, 29, 740-770.

Plaza, F. (2000). Evaluating the influence of a large cultural artifact in the attraction of tourism: The Guggenheim Meuseum Bilbao case. Urban Affairs Review, 36(2), 264-274.

Portes, A. (1998). Social capital: Its origins and applications in modern sociology. Annual Review of Sociology, 24, 1-25.

Portes, A., \& Landolt, P. (1996). The downside of social capital. The American Prospect, 26, 18-23.

Prior, J. U., \& Tavano Blessi, G. (2011). How does culture-led urban transformation affect the social and human capital of suburban residents: Evidence from the Sydney Olympic Park experience. Milan, Mimeo: IULM University.

Putnam, R. D. (2001). Social capital, measurement and consequence. Canadian Journal of Policy Research, 1, 41-51.

Roberts, P. (2000). The evolution, definition and purpose of urban regeneration. In P. Robert \& K. Sukes (Eds.), Urban regeneration handbook. London: Sage.

Sacco, P. L., \& Tavano Blessi, G. (2009). The social viability of culture-led urban transformation processes: Evidence from the Bicocca District, Milan. Urban Studies, 46(5/6), 1115-1135.

Sasaki, M. (2010). Urban regeneration through cultural creativity and social inclusion: Rethinking creative city theory through a Japanese case study. Cities, 27(Suppl. 1), 3-9.

Scott, A. (2000). The cultural economy of cities. London: Sage.

Sharp, J., Pollock, V. L., \& Paddison, R. (2005). Just art for a just city: Public art and social inclusion in urban regeneration. Urban Studies, 42(5/6), 1001-1023.

TOHU (2006) Tohu. Un modèle de développement durable au cœur du quartier SaintMichel. Montréal, TOHU. 10.

Tremblay, D. G., \& Pilati, Thomas. (2008). The Tohu and artist-run centers: Contributions to the creative city? Canadian Journal of Regional Science, 30(2), 337-356.

Tremblay, D. G., \& Tremblay, R. (2006) (Eds.), La compétitivité urbaine à l'ère de la nouvelle économie: enjeux et défis. Québec, Presses de l'université du Québec.

Tremblay, D. G. (2006). Networking, clusters and human capital development. Research report (40pp). <http://www.teluq.uqam.ca/chaireecosavoir/pdf/ NRC06-08A.pdf>.

Tremblay, R., \& Tremblay, D. G. (2010). La classe créative selon Richard Florida: un paradigme urbain plausible? Québec-Rennes: Presses de l'université du Québec and Presses universitaires de Rennes. <http://www.puq.ca/media/produits/ documents/456_D2509_FPR.pdf>.

Young, G. (2006). The Ashgate research companion to planning and culture. London: Ashgate. 